Original Research

\title{
Dome-Basin Structure and its Influence on Coal and Gas Outbursts
}

\author{
Deyu Xu*, Deyong Guo \\ China University of Mining and Technology, Faculty of Resources and Safety Engineering, Beijing, China
}

Received: 17 January 2017

Accepted: 3 October 2017

\begin{abstract}
Coal and gas outbursts are extremely violent dynamic disasters. Geological structure is the primary factor for controlling outbursts, and dome-basin structure is one of the most dangerous structural types that are prone to cause outbursts. This study reveals the reasons for and characteristics of coal and gas outbursts in a dome-basin structure. According to the analysis of the features and the formation mechanism of a dome-basin structure, combining gas geology theory and gas geology parameters, coal seam characteristics of stress and strain, coal-body structure, and coal seam gas occurrences in a domebasin structure were studied. Based on the change laws of the above three aspects, the influences of domebasin structure on coal and gas outburst was also further analyzed. The results show that the dome-basin structure can be divided into three parts: dome structure, basin structure, and saddle structure. In the saddle structure, the surrounding rock was greatly damaged and the elasticity of the rock strata increased. It is easy to incur tectonic stress concentration. The type of coal-body structure is most of the mylonitic coal of full-layer thickness, and decreased the destruction-resisting ability of a coal seam. Coal seam gas content and pressure are relatively large, and provided beneficial conditions for the coal and gas outburst. Because of these effects, the probability of coal and gas outbursts visibly increased in this area.
\end{abstract}

Keywords: dome-basin structure, deformed coal, coal seam gas, coal and gas outburst

\section{Introduction}

Coal and gas outburst is a complicate violent geological dynamic disaster, and it brings a huge threat to underground mining engineering and coal miners' lives. Comprehensive statistics have indicated that the geological structure is the primary factor for controlling coal and gas outbursts, and more than $80 \%$ of coal and gas outbursts occurred in the fracture zones of geological structures, therefore the fold structure is one of the zones which it is most likely to cause such an outburst [1-2]. In

*e-mail: tgzyxdy@163.com order to predict outburst zones more scientifically and to ensure that workers are in a safe working environment, many coalfield geological scholars have conducted a large amount of research on the fold structure and its influences on coal and gas outbursts, such as the relationship between fold geometry characteristics and outburst zones [3], the effects of fold dynamic characteristics on outbursts [4-6], and the distribution features of the deformed coal and gas occurrence in different fold types [7-8]. Recent developments have concentrated to reveal the main geological control factors of outburst in fold structure. In the research, compression action created by tectonic movement was regarded as the main reason for gas accumulation and the outburst [9-13]. Meanwhile, 


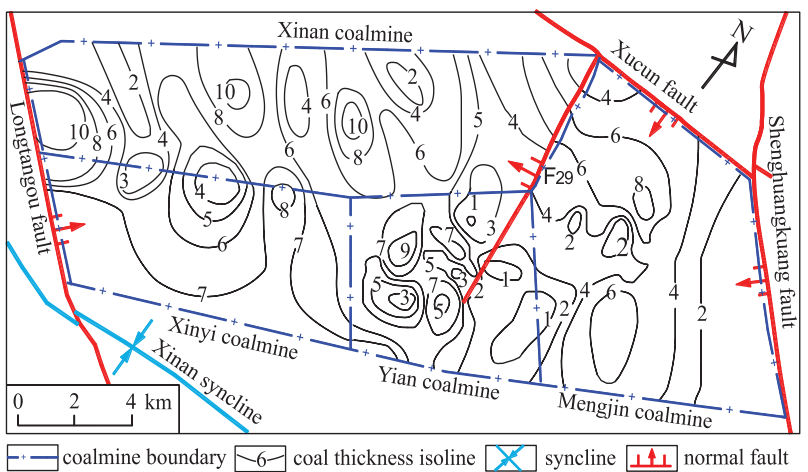

Fig. 1. Structural sketch of Xinan coalfield and the change of thickness.

the change of tectonic stress in different zones of the fold structure was considered the dynamic cause for the outburst [14-15]. Besides, structural deformed coal (which is often generated in the axis of the fold) was discussed as a very significant reason for an outburst because of its largely varied gas desorption and diffusion properties [1619]. But according to the related research, the coalfield mostly experienced the multi-period tectonic movement, and in the superposition zone of the structural system, the damage degree of the coal-rock strata was often intense, and coal and gas outburst was prone to happen [20-21]. However, the study on the fold superposition and its effects on coal and gas outburst is relatively less.

A dome-basin structure was formed by the superposition of the fold structures that were generated in two stages or multi-stage tectonic movements. In the mining practices, the coal and gas outburst occurred frequently and the dangerousness increased greatly in the areas of the dome-basin structure. However, studies about the controlling action of the dome-basin structure on outbursts are relatively scarce. In this study, Xinan coalfield was the research area. The formation mechanism and the characteristics of the dome-basin structure were studied, and according to the gas geology theory and a large amount of gas geological parameters, the influences of the dome-basin structure on the stress-strain features of coal-rock seams, coal-body structure, and coal seam gas occurrence were analyzed. The control effects of dome-basin structure on the coal and gas outburst were also studied further.

\section{Materials and Methods}

\section{Geological Features and Paleotectonic Stress Field}

\section{Geological features}

Xinan coalfield is located in western Henan Province, China. It belongs to the northern margin of the Qinling orogenic belt. In this region, large or medium-sized geological structures are less common and are mainly located along the border of the coalfield (Fig. 1). Xinan syncline is the major structure of the coalfield, and it controls the structural form of the coalfield as well. The geological structure in Xinan coalfield is simple. It is a wide flat monoclinal structure, south trend, strike direction $40^{\circ}$, dip $130^{\circ}$, and angle of dip $6 \sim 14^{\circ}$. The coal measures of this area were formed in the late Carboniferous and the early Permian periods. It mainly experienced the Indosinian, Yanshanian, and Himalayan tectonic movements. The structures generated in the Himalayan movement were mainly NE-trending in the adjacent areas [22-23]. The large or medium-sized geological structures of NE-trending don't exist in this area (Fig.1), which suggests that Himalayan tectonic movement was not strong in this area. The Indosinian and Yanshanian tectonic movements were the primary control factors for generating geological structures. However, the multi-stage tectonic movements generated many smallsized fold structures, and resulted in drastic changes of the thickness of the main working coal bed (Fig. 1). The average value of variation coefficient of coal layer thickness reached up to $68 \%$, and it increased up to $79 \%$ in some areas. The coal-body structure was badly damaged for the effects of multi-stage tectonic movements, and the granular and scaled coal is the primary component

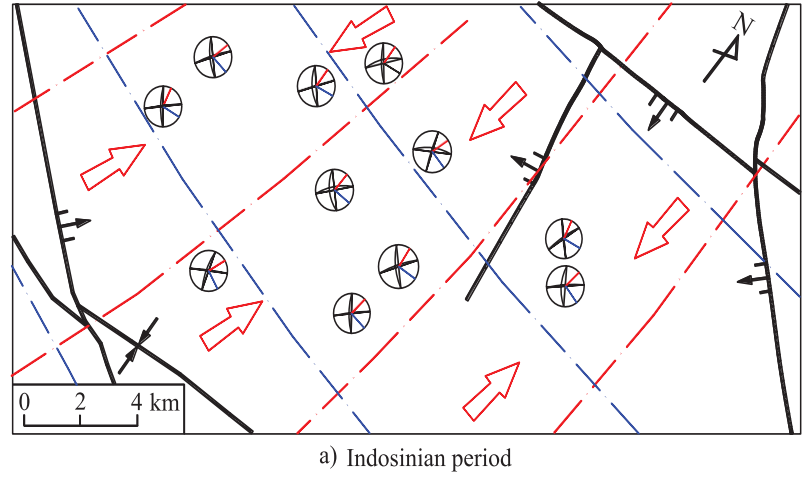

$X$ syncline $\perp \mathbb{1}$ normal fault $\quad . \quad \begin{aligned} & \text { trajectory of maximum } \\ & \text { principle stress }\end{aligned}$

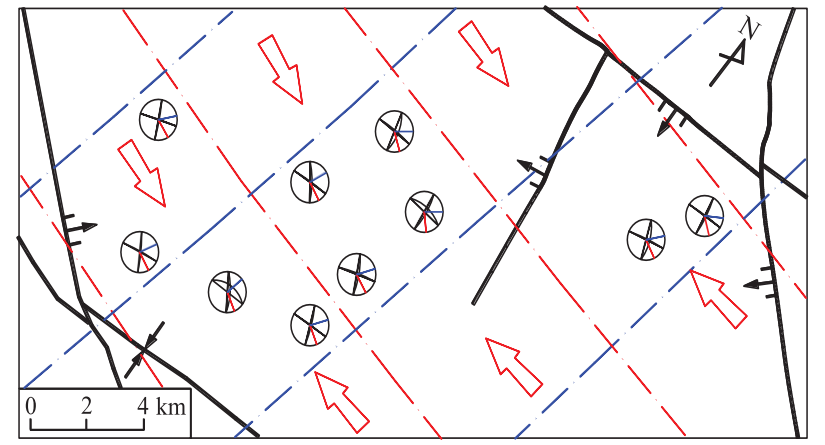

b) Yanshanian period

trajectory of minimum principle stress
$\Rightarrow$ compression

(1) stereographic projection

Fig. 2. Indosinian and Yanshanian tectonic stress field. 
of a coal seam. The radical changes of coal thickness and the widespread deformed coal caused by the fold are the primary structural deformation characteristics in Xinan coalfield. The coalfield contains four coal mines (Fig. 1), and they were all identified as the coal and gas outburst mine.

\section{Paleotectonic Stress Field}

The structures of Xinan coalfield are relatively simple. The $\mathrm{x}$ conjugate shear joint was used to recover the paleotectonic stress field on the basis of the analysis of the regional geological background. In the study area, 21 groups of conjugate shear joints were observed and selected to assess the paleotectonic stress field. The results show that all conjugate shear joints could be divided into 2 sets (Fig. 2), and the stress state of each point was also analyzed using the stereographic projection of each joint. Connect the same principal stress direction of each point according to the broken line to obtain the directions of the Indosinian and Yanshanian tectonic stress field (Fig. 2). On the basis of the characteristics of the Indosinian and Yanshanian tectonic stress field, the compression direction in the Indosinian period was NS-trending, and in the Yanshanian period it changed to EW-trending.

\section{Evolution and Characteristics of Dome-Basin Structure}

\section{Evolution of Dome-Basin Structure and its Control Range}

The dome-basin structure is a complex fold form, and its formation mechanism was explained in detail by Ramsay as a result of fold superposition (Fig. 3). Domebasin structure is mainly superposed by horizontal and upright folds in two stages [24]. The main forming condition is the intersecting of the two-fold axis in large angle or a rectangle (Fig. 3). The structure of Xinan coalfield is relatively simple and is mainly a wide flat monoclinal structure. Many horizontal and upright folds have been generated in this region because of the effect of the tectonic compression action in Indosinian and Yanshanian. Based on this reason, and according to the tectonic stress field in Indosinian and Yanshanian (Fig. 2), the intersectant angle of the principal stress direction

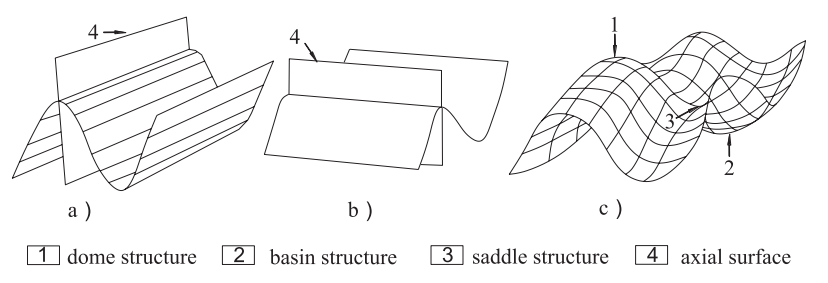

Fig. 3. Sketches showing evolutionary processes of domeand-basin pattern: a) fold morphology in early period, b) fold morphology in later period, c) dome-basin structure after fold superposition. in two stages was considerable and provided favorable conditions for the generation of the dome-basin structure.

In the western part of Xinan coalfield, such as Xinan and Xinyi coal mines, the coal thickness nearly changes along with NS trending (Fig. 1) and was mainly influenced by the small folds structure created in Indosinian. However, in the southern part of Mengjin coal mine, the coal thickness nearly changes along the EW trending and was mainly created by the folds generated in Yanshanian. As mentioned above, the Yian coal mine in the middle part of the coalfield is located in the composite part of the two regions (Fig. 1). Therefore, the fold structures generated in the two periods were superposed in this area, and made the thickness of the coal changes dramatically. The coal thickness isoline in this area is shown as closed loops (Fig. 1), and shows that the distribution form of coal seam primary is presented as continuous convex and concave structures that correspond to the structural form of the dome-basin structure, respectively. Therefore, this area is the major control region of the dome-basin structure in Xinan coalfield.

\section{The Characteristics of Dome-Basin Structure}

The dome-basin structure is composed of three main parts (Fig. 3). The superposition area of antiforms in two periods forms the dome structure. The superposition area of synforms in two periods forms the basin structural. In the superposition area of late antiform and early synform, the antiform hinge plunged and the synform rose, and forms the saddle structure [24]. However, in the coal measures the performance type of dome-basin structure is different from the single rock stratum. The coal seam is embedded in the soft and hard alternated rock stratums and is the incompetent bed. The shape is controlled by the surrounding competent bed. The coal seam adjusts the folds deformation of the roof and floor from the coal rheological or sliding, and the results are presented as the change of coal seam thickness [25]. According to the deformation shapes of the roof and floor of coal seam, and the change rule of coal thickness isoline in this area, the characteristics of dome-basin structure and the constituent parts can be identified.

In the coal measures, the roof of the coal seam is medium sandstone (Fig. 4), the average value of thickness is $16.6 \mathrm{~m}$, and the uniaxial compressive strength reaches up to $86 \mathrm{MP}$, which is the primary competent bed and deformation layer. The floor of the coal seam is fine-grain sandstone, the average value of thickness is $5.2 \mathrm{~m}$, and uniaxial compressive strength reaches up to $52 \mathrm{MP}$, and the competent and deformation degree is weaker than the roof. Because of the comprehension effect of fold deformation of the roof and floor, the coal seam primarily presents the shape of convex or concave on the structural section (Fig. 4), which resulted in dramatic changes to coal seam thickness, and the thickness isoline of coal seam is presented as closed-loop in the shape of a concentric ring (Fig. 5). Therefore, in the area of dome structure, the coal-rock strata shows top thick fold, the rising degree 
a)

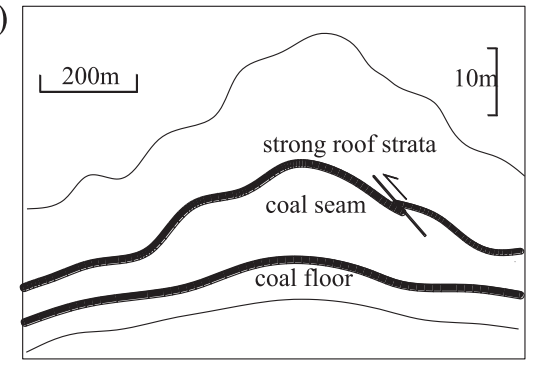

b)

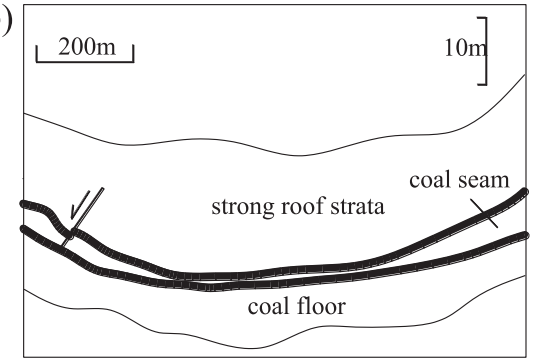

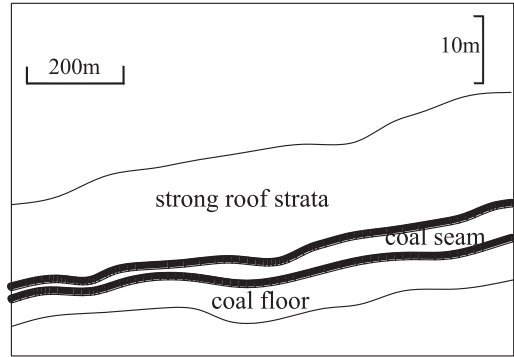

Fig. 4. Sketches showing geometric features of coal measures in each part of the dome-basin structure in Xinan coalfield: a) dome structure section, b) basin structure section, c) saddle structure section.

of the roof exceeds the floor, and the coal seam shows as convex (Fig. 4a). The coal thickness isoline increases gradually from the external totheinternalofconcentricrings (Fig. 5), and the thickness reaches up to $14 \mathrm{~m}$. In the area of the basin structure the coal-rock strata shows supratenuous fold, the sunken degree of the roof exceeded the floor, and the coal seam is presented as concave (Fig. 4b). The coal thickness isoline decreased gradually from the external to the internal of concentric rings (Fig. 5), and the coal thickness decreased to below $2 \mathrm{~m}$. In the area of saddle structure that is similar with the dome structure, the coal seam thickness increased. However, the rising degree of the roof and floor, coal seam thickness, and the thickening rate of coal seam are lower than the dome structure (Fig. 4c). The coal seam often shows as slender coal belts. The coal thickness isoline presents as anisometric ellipticity, the values of the coal thickness isoline increased gradually along the rising end of synform (Fig.5), and the coal seam thickness reached up to $5 \mathrm{~m}$. Meanwhile, the dome and basin mainly appeared continuously and alternately along the principal

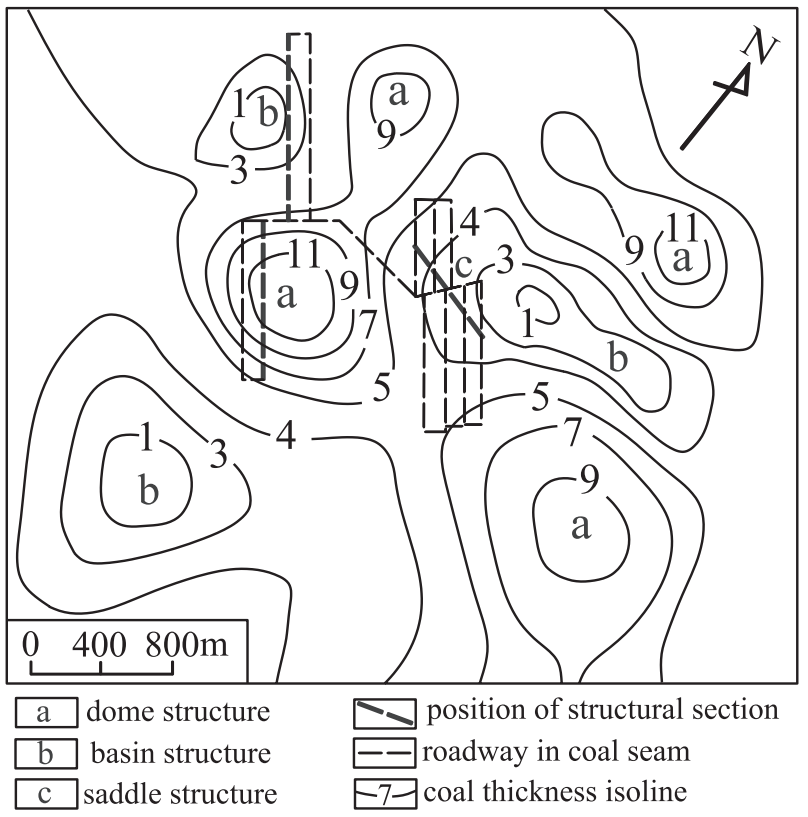

Fig. 5. Change characteristics of coal thickness in dome-basin structure of Yian coal mine. stress direction of the tectonic stress field. The saddle structure developed in the combination parts of the early synform and the late antiform (Fig. 5).

\section{Results and Discussion}

\section{The Influence of Dome-Basin Structure on Outburst Factors}

\section{The Stress-Strain Characteristics of Coal and Rock}

Tectonic stress plays a dominant role in the coal and gas outbursts. The tectonic stress in the coal seam has a great relationship with the elasticity of surrounding rock. When the extrusion stress is the same, the rock stratum of high elasticity is more likely to deform, then it extrudes the coal-body and results in the tectonic stress concentration in coal seam, which provided momentum for outbursts [14].

The roof of No. 21 coal seam of Xinan coalfield is the most competent bed of coal measures. It's the main part of tectonic deformation. In this area, the lithology and thickness of roof strata show little change. The elasticity of rock stratum is closely related to the rock structure and the damage degree. Compared with the area of no

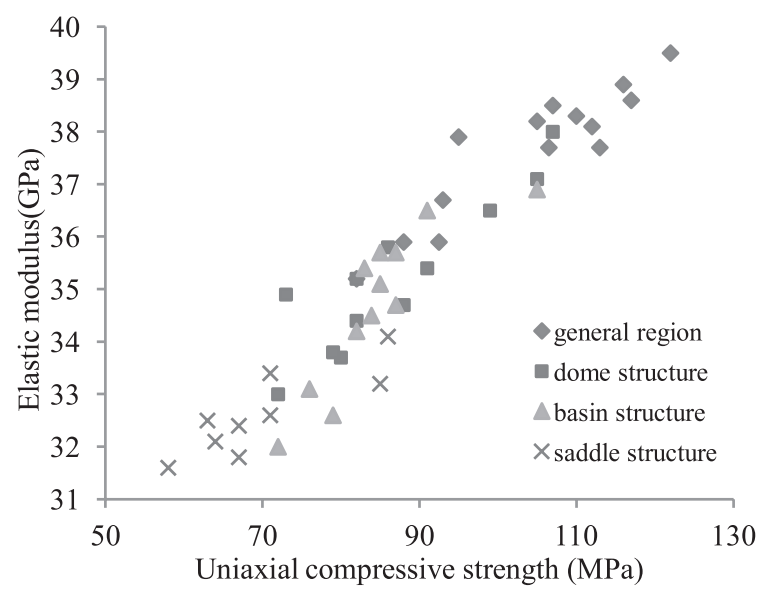

Fig. 6. Elastic modulus and uniaxial compressive strength of coal roof in dome-basin structure of Xinan coalfield. 
fold superposition, the area of dome-basin structure was influenced by the two phases of paleotectonic tectonic movement, the fracture of the roof strata increased, the damage degree of coal-body increased, the anti-pressure ability of rock strata decreased, and the elasticity increased. The test results of the uniaxial compressive strength and the elasticity modulus showed that in the area of dome-basin structure, the uniaxial compressive strength was mostly below $90 \mathrm{MP}$, and the elasticity modulus was mostly below $35.8 \mathrm{GPa}$, which decreased obviously compared with the general zones (Fig. 6). In the area of dome-basin structure, the elasticity modulus increased. It is more likely to result in the elastic deformation, extrude the coal seam, and then cause the concentration of tectonic stress.

However, in the internal dome-basin structure, the saddle structure experienced the early synform deformation and late antiform deformation. The difference of the deformation types of the two-stage structure resulted in the roof strata suffering from damage of two types. The damage degree of roof strata reached up to the highest, the uniaxial compressive strength was as low as $58 \mathrm{MP}$, the elasticity modulus was as low as $31.4 \mathrm{GPa}$ (Fig. 6), and the elasticity is the highest. In the area of the dome structure and basin structure, the deformation types and the function of the two-stage structures were the same. Therefore, the damage degree of rock takes second place, and the elasticity was relatively smaller. According to the analysis of the elasticity of rock strata, the elasticity of rock strata is the highest in the saddle structure of the internal of dome-basin structure, and the coal seam is easy to be extruded. The saddle structure is the area that is easy to result in tectonic stress concentration.

\section{Coal Body Structure Characteristics}

The deformed coal is an important factor to control the coal and gas outburst. The strength of the deformed coal is low, and decreases the resistance of coal and gas outburst. Related research shows that the type and the thickness of deformed coal are closely related with the coal and gas outburst. The area that develops mylonite coal with relatively large thickness is extremely easy to cause the coal and gas outburst [26-29].

In the three parts of dome-basin structure of Xinan coalfield, the types and the thickness of deformed coal are greatly different (Fig. 7). In the area of dome structure, the roof of the coal seam rises upwards and forms the phenomenon of detachment structure. The coal seam slid into detachment structure and became thick. The coal is mainly of scaled coal because of the influence of sliding shear (Fig. 7a), the thickness of the coal seam is relatively large, and reached up to $10 \mathrm{~m}$. The damage degree of the coal was relatively low, and the protodyakonov coefficient is above 0.3 (Table 1). Granular coal often accompanied the layer of scaled coal (Fig. 7a). The granular layer angle is relatively large and thrusts up to the roof. The granular layer was the major sliding face, the thickness of the granular coal is much thinner than the scaled coal layer, and the protodyakonov coefficient is below 0.28 (Table 1).

In the middle area of basin structural, the coalbody structure was seriously damaged for the vertical extrusion of the roof. The coal is mostly mylonite coal of full-layer thickness (Fig. 7b). The maximum value of the protodyakonov coefficient is only 0.18 , the thickness is relatively small and is below 1.5 meters. In the area that is away from the central basin, the vertical extrusion of the roof decreased. The coal-body structure grew into the granular coal of full-layer thickness gradually, and the protodyakonov coefficient is between 0.16 and 0.28 (Table 1). The thickness of the broken coal increased with the increase of the coal seam thickness, and reached up to $4 \mathrm{~m}$ (Fig. 7b).

The deformation form of saddle structure was the same as the basin structure in the earlier period. The saddle structure was affected by the fold deformation of the early synform, and the coal-body structure was badly damaged for the roof extrusion. The mylonitic coal was developed of full-layer thickness (Fig. 7c). But in later period, the coal seam thickness increased along with the early synform to the rising end of the late antiform. The thickness of the previously generated mylonitic coal also increased, the thickness increased slowly and reached up to $5 \mathrm{~m}$ in the rising end of the late antiform (Fig. 7c). The protodyakonov coefficient is relatively low and is below
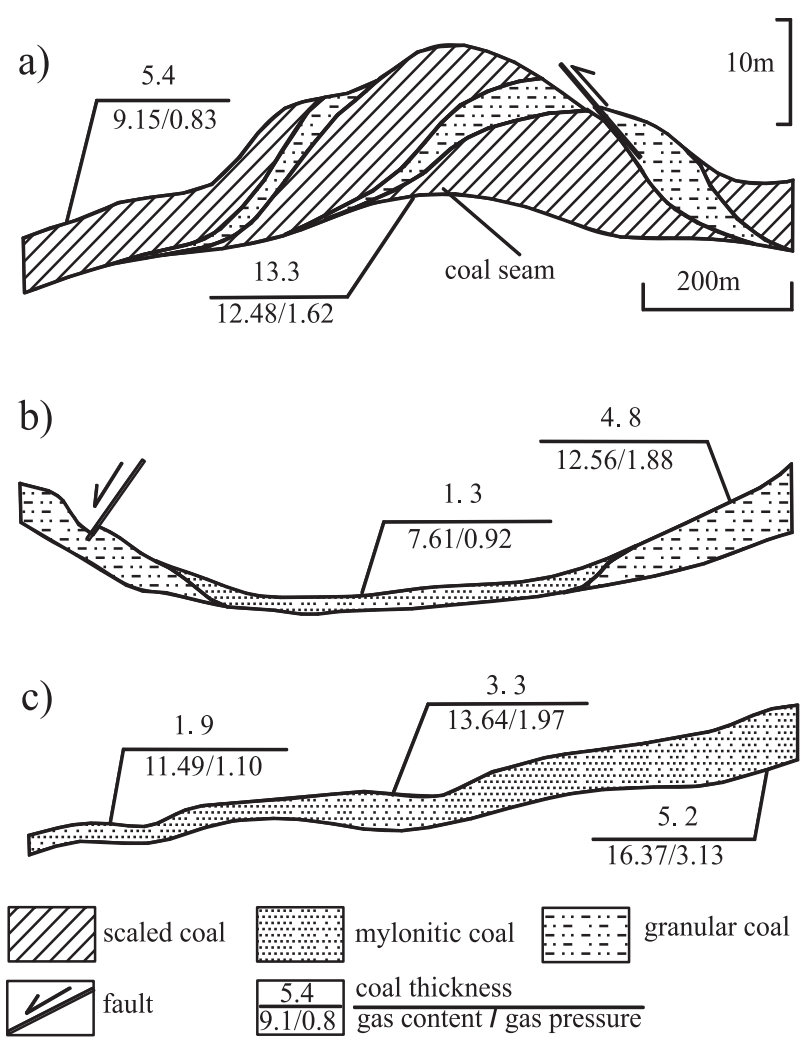

Fig. 7. Coal structure and gas occurrence in dome-basin structure of Xinan coalfield: a) dome structure section, b) basin structure section, c) saddle structure section. 
Table 1. Coal structure characteristics in dome-basin structure.

\begin{tabular}{|c|c|c|c|c|}
\hline \multirow{2}{*}{ Region } & \multirow{2}{*}{$\begin{array}{l}\text { Coal thickness } \\
\text { (m) }\end{array}$} & \multicolumn{3}{|c|}{ Coal body structure characteristics } \\
\hline & & Deformed coal type & Thickness (m) & f \\
\hline General region & $4.1-6.2$ & Cataclastic coal & $4.1-6.2$ & $0.35-0.64$ \\
\hline \multirow{2}{*}{ Dome structure } & \multirow{2}{*}{$5.3-14.2$} & Scaled coal & $3.5-10.7$ & $0.34-0.45$ \\
\hline & & Granular coal & $1.1-4.2$ & $0.16-0.28$ \\
\hline \multirow{2}{*}{ Basin structure } & \multirow{2}{*}{$0-6.3$} & Granular coal & $1.2-5.4$ & $0.14-0.31$ \\
\hline & & Mylonitic coal & $0-1.5$ & $0.09-0.18$ \\
\hline Saddle structure & $0-5.1$ & Mylonitic coal & $1-5.1$ & $0.09-0.15$ \\
\hline
\end{tabular}

$f$ - protodyakonov coefficient

0.15 (Table 1). The rising end of the late antiform is the maximum thickness area of the mylonitic coal in the saddle structure.

\section{Gas Occurrence Characteristics}

The coal seam gas content is the uppermost factor to control the coal and gas outburst [30], which is mainly related with the gas generation and gas preservation condition [31]. For the gas generation, the degree of coal metamorphism is the primary factor to influence gas generation, and the gas generation increases with the degree of coal metamorphism [32]. The coal volatile matter is the important index to evaluate the degree of coal metamorphism, and decreases with the increase of the degree of coal metamorphism. From lignite to anthracite, coal volatile mater decreases from 50 to $5 \%$. In the area of dome-basin structure, the basin structure and the saddle structure suffered from the extruding deformation of the roof. The tectonic metamorphism function resulted in the increase of the degree of coal metamorphic, the coal volatile mater decreased as low as 9.15 percent (Table 2), and coal seam gas generation increased. In the area of dome structure, the deformation of the roof antiform formed the phenomenon of detachment structure and coal seam thickness increased by the shear-sliding. The degree of coal metamorphism increased slightly more than the general region, and the gas generation ability of coal seam was lower than the area of the saddle structure.
The gas preservation condition has an important influence on the gas content of coal seam. Structural closure, hydrological characteristics, burial depth, coal seam thickness, coal body adsorption, and so on are the main factors affecting coal seam gas preservation. In Xinan coal field, the area is dominated by medium and small folds and fewer fault structure existed. The structure is overall well closed, and it made the structural closure have a high degree and does not change much. At the same time, the groundwater is not developed in mining area, and the burial depth of the coal seam in mining area is almost at a same level. The above three aspects of gas preservation conditions have little effect on the coal seam gas content in this area and for gas preservation, so coal seam thickness and coal adsorption are the primary factors to influence gas preservation. Firstly, the coal seam is a gas insulation barrier. The upper coal seam obstructs the gas escape of the middle-low coal seam, which is beneficial to gas preservation [33]. In the area of basin structure, the degree of coal metamorphism is high and the adsorption ability is strong. But the coal seam thickness of basin structure is much thinner than other areas (Fig. 7), which is bad for the coal seam gas preservation and results in the gas content being not particularly large. In the area of dome structure, the coal seam thickness is large. But the deformed coal is undeveloped and the adsorption ability is weak. The adsorption constant $a$ is even at a low degree of 35.3 (Table 2), which indicates that it is bad for gas preservation. Meanwhile, the degree of coal metamorphism is also low (Table 2), gas generation

Table 2. Gas occurrence and its control factors in dome-basin structure.

\begin{tabular}{|c|c|c|c|c|}
\hline Region & $\begin{array}{c}\mathrm{V}_{\text {daf }} \\
(\%)\end{array}$ & $\begin{array}{c}\mathrm{a} \\
\left(\mathrm{cm}^{3} / \mathrm{gr}\right)\end{array}$ & $\begin{array}{c}\text { Gas content } \\
\left(\mathrm{m}^{3} / \mathrm{t}\right)\end{array}$ & $\begin{array}{c}\text { Gas pressure } \\
(\mathrm{MPa})\end{array}$ \\
\hline General region & $14.67 \sim 17.73$ & $28.6 \sim 46.7$ & $7.97 \sim 11.63$ & $0.32 \sim 0.96$ \\
\hline Dome structure & $12.18 \sim 17.14$ & $35.3 \sim 48.3$ & $9.15-12.48$ & $0.83 \sim 1.62$ \\
\hline Basin structure & $9.15 \sim 14.46$ & $44.6-52.8$ & $7.61 \sim 12.56$ & $0.92-1.88$ \\
\hline Saddle structure & $9.46 \sim 13.89$ & $42.5 \sim 56.9$ & $11.49 \sim 16.37$ & $1.10 \sim 3.13$ \\
\hline
\end{tabular}

$a$ - adsorption constant, $V_{d a f}$ - volatiles 


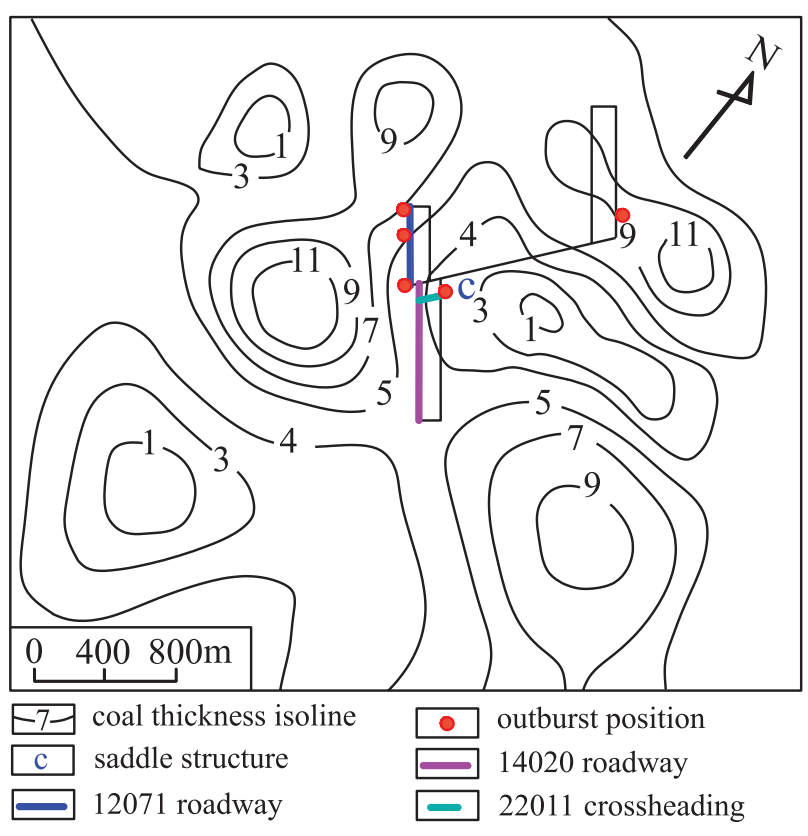

Fig. 8. Distribution and location of coal and gas outburst in Yian coal mine

was little, and gas content is relatively low on the whole. However, in the area of saddle structure, the thickness of the mylonitic coal increased and reached up to $5 \mathrm{~m}$. On the one hand, the breathability of the extremely thick mylonitic coal is poor and obstructed the gas escape. On the other hand, the absorption ability of the mylonitic coal is strong, and the adsorption constant $a$ reached up to 56.9 (Table 2), which was extremely beneficial to gas preservation. On the whole, the gas content in the area of saddle structure is relatively large. It increases with the thickening of mylonitic coal and reached up to $16.37 \mathrm{~m}^{3} / \mathrm{t}$.

\section{The Influence of Dome-Basin Structure on Coal and Gas Outburst}

The coal and gas outburst is a combination result of tectonic stress, the physical and mechanical properties of coal, and coal seam gas. Tectonic stress and coal seam gas provide momentum for coal and gas outburst. However, the deformed coal decreases the resistance for coal and gas outburst. The strong ability of absorption and desorption gas of the deformed coal also provides advantages for coal and gas outburst. Therefore, the three factors control the dangerousness and characteristics of coal and gas outburst.

In the three parts of dome-basin structure of Xinan coalfield, the damage degree of the surrounding rock was high and the elasticity of the rock strata increased in the area of the saddle structure. It is easy to extrude the coal-body and incurs the tectonic stress concentration. Moreover, in the saddle structure, the coal seam gas content and the stress are large, and reach up to $16.37 \mathrm{~m}^{3} / \mathrm{t}$ and 3.1MP, respectively. The two factors provide the uppermost motivation for the coal and gas outburst. Meanwhile, the major coal-body structure is mylonitic coal of full-layer thickness, and the thickness exceeded $5 \mathrm{~m}$, which decreases the destruction-resisting ability and provides extremely favorable conditions for coal and gas outburst. However, in the area of dome structure, the damage degree of the coal decreased, and the deformed coal was more undeveloped than the saddle structure. In the basin structure area, although the deformed coal is mainly the mylonitic coal of full-layer thickness, the thickness is relatively small and is often below $1.5 \mathrm{~m}$. The gas content decreased obviously in the area of the dome structure and the basin structure than that in the saddle structure, and the outburst dangerousness of the two areas is smaller as well. Analysis of the three factors show that in the saddle structure area of the dome-basin structure is the most dangerous and probable area for the coal and gas outburst.

The production practice of Yian coal mine showed that the chance of outburst increased significantly in the area of the saddle structure. 14020 roadway in Yian coalmine is as long as $800 \mathrm{~m}$ and can be divided into two parts according to its location. The first part is the range of between 0 and $400 \mathrm{~m}$, located in the area of saddle structure. The second part is the range of the other $400 \mathrm{~m}$, and is far away from the saddle structure gradually (Fig. 8). In the Yian coal mine, three indexes were used to predict the outburst, and it includes drilling cuttings of the coal, gas desorption of the drilling cuttings, and the initial velocity of gas emissions from the drilling hole. The change degree of the first two indexes is not obvious and there was no overrun phenomenon of the two indexes. Only the initial velocity of gas emission from the drilling hole $q$ can be used as an sensitive index for coal and gas outburst, and its critical value is 3.5. In the first part, the values of $q$ exceeded the limit of 3.5 for 18 times

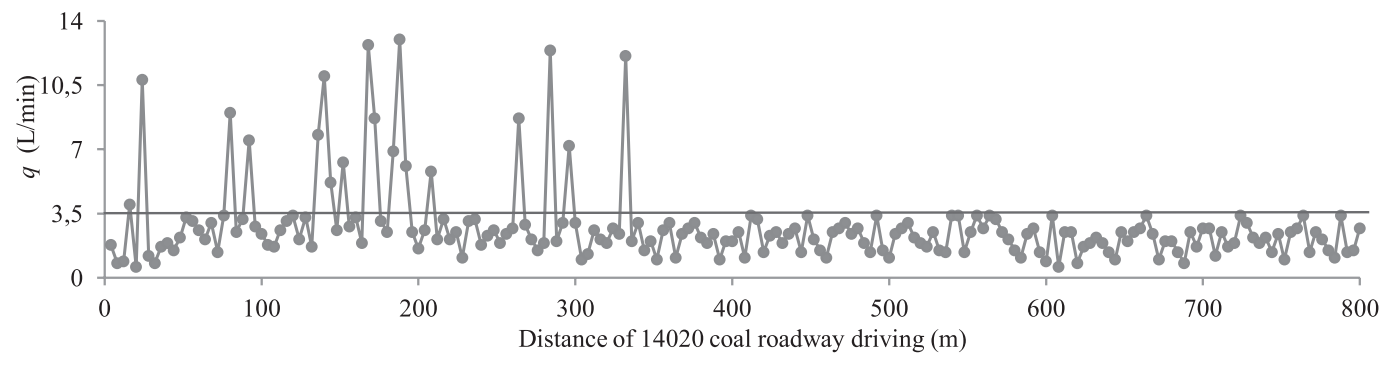

Fig. 9. Change characteristics of outburst prediction index in 14020 drivage face 
Table 3. Substance compositions of outburst and deformed coal characteristics in outburst point.

\begin{tabular}{|c|c|c|c|c|c|}
\hline \multirow{2}{*}{ Outburst position } & \multicolumn{2}{|c|}{ Substance compositions of outburst } & \multicolumn{2}{c|}{ Deformed coal } \\
\cline { 2 - 6 } & $\begin{array}{c}\text { Gas } \\
\left(\mathrm{m}^{3}\right)\end{array}$ & $\begin{array}{c}\text { Coal } \\
(\mathrm{t})\end{array}$ & $\begin{array}{c}\text { Gas emission } \\
\left(\mathrm{m}^{3} / \mathrm{t}\right)\end{array}$ & $\begin{array}{c}\text { Thickness } \\
(\mathrm{m})\end{array}$ \\
\hline Main roadway & 10432 & 247 & 54 & Mylonitic coal & 5.1 \\
\hline 12071 Roadway & 408 & 14 & 29 & Mylonitic coal & 4.2 \\
\hline 12071 Roadway & 495 & 12 & 45 & Mylonitic coal & 4.3 \\
\hline 22011 Crossheading & 5700 & 38 & 150 & Mylonitic coal & 4.8 \\
\hline 12011 Crossheading & 151 & 15.9 & 9.5 & Scaled coal & 11.2 \\
\hline
\end{tabular}

when drivaging, and mostly of which were above 7 , the maximum values reached up to 13 (Fig. 9). In the second part, the values of $q$ were all below 3.5 and didn't exceed the critical value. In the area of dome structure and basin structure, the values of $q$ did not exceed the critical value as well. The exceeded times are far more than that in other areas. Furthermore, in the area of saddle structure of the 14020 roadway, the undulation was strong, illustrating that the chance of outburst in the area of saddle structure was much higher than other areas. Meanwhile, coal and gas outbursts have happened five times in Yian coal mine and four of them focused in the rising end of the saddle structure (Fig. 8), which accounted for $80 \%$ of the total number of the outburst. The characteristics of the four coal and gas outburst accidents showed that the thickness of mtlonitic coal exceeded $4.2 \mathrm{~m}$, the gas emission quantity was often relatively large and reached up to $150 \mathrm{~m}^{3} / \mathrm{t}$ (Table 3), which increased the dangerousness of coal and gas outburst greatly. While in other areas, the coal structure is mainly scaled coal. In the north of Yian mine, there is a single outburst point (Fig. 8), but the reason for this occurrence is different. The reason for the outburst is mainly the large degree of coal thickness. The thickness of the coal seam in this area is as high as $11.2 \mathrm{~m}$ (Table 3 ), and its huge gravity caused the upper coal body to fall off and cause the outburst. The danger of the outburst is much lower than the area of saddle structure. The gas emission quantity in this outburst was only $9.5 \mathrm{~m}^{3} / \mathrm{t}$, and there was only one outburst in this area. The research showed that the area of saddle structure is the highest area for danger of coal and gas outburst, and is the major reason for the increase of danger of coal and gas outburst in the dome-basin structure areas. In addition, outburst danger increases with the increase of the myloniticc coal thickness in this area.

\section{Conclusions}

The structure in Xinan coalfield is simple and mainly develops the vertical and horizontal folds. The principal stress direction of tectonic stress of the Indosinian and Yanshanian intersected with large angles, and provided conditions for the formation of dome-basin structure. The dome-basin structure mainly presents the alternate types of convex and concave. The Yian coal mine in the middle of the coalfield is the primary developed area of the dome-basin structure.

The dome-basin structure can be divide into three parts: dome structure, basin structure, and saddle structure. In the area of saddle structure of the dome-basin structure, the surrounding rock was greatly damaged and the elasticity of the rock strata increased. It is easy to incur the tectonic stress concentration. The type of coalbody structure is most of the mylonitic coal of full-layer thickness, and decreased the destruction-resisting ability of coal seam. The coal seam gas content and pressure are relatively large, and provided beneficial conditions for the coal and gas outburst.

The comprehension function of the tectonic stress, the deformed coal, and the coal seam gas resulted in the saddle structure being the most probable area to occur coal and gas outburst in the dome-basin structure, and the danger of coal and gas outburst increases with the increase of thickness of the mylonite coal in this area.

\section{Acknowledgements}

This work was supported by the Key Program of National Natural Science Foundation of China (No. 41430640).

\section{References}

1. SHEPHERD J., RIXON L.K., GRIFFITHS L. Outbursts and geological sructures in coal mines: A review. Int. J. Rock. Mech. Min. Sci. 18, 267, 1981.

2. WANG H., WANG L., CHENG Y., ZHOU H. Characteristics and dominant controlling factors of gas outburst in Huaibei coalfield and its countermeasures. Int. J. Rock. Mech. Min. Sci. 23, 591, 2013.

3. HE J., LIU M., YAN A. Fractal research of relation between geological tectonic coalfields and gas outburst. J. China. Coal. Soc. 27 (6), 623, 2002.

4. WANG S., WANG G., CHANG Q, ZHANG T., WANG $Z$. Controlling effect of the fold neutral plane on coalbed. Coal. Geo. Explor. 34 (4), 16, 2006.

5. HAN J., ZHANG H., HUO B. Discussion of coal and gas outburst mechanism of syncline. J. China. Coal. Soc. 33 (8), 908, 2008. 
6. FRODSHAM K., GAYER R.A. The impact of tectonic deformation upon coal seams in the South Wales coalfield, UK. Int. J. Coal Geol. 38, 297, 1999

7. KANG J. The basic types of gas controlled by fold structures. Coal. Geo. Explor. 22 (1), 30, 1994.

8. ZHU Z., SONG W., CUI H. The study of syncline controlling coalbed methane in Wangying-Liujia district in Fuxin coalfield. Nat. Gas. Geosci. 15 (6), 673, 2004.

9. BAO Y., WEI C., NEUPANE B. Generation and accumulation characteristics of mixed coalbed methane controlled by tectonic evolution in Liulin CBM field, eastern Ordos Basin, China. J. Nat. Gas. Eng. 28, 262, 2016.

10. WEI G., WANG B., YAN J., WANG W., JIA T., WANG Y. Gas geological control characteristics of outbursts coal seam in Pingdingshan No. 8 Mine. J. China. Coal. Soc. 40 (3), 555,2015

11. WANG L., CHENG Y., AN F., ZHOU H., KONG S., WANG W. Characteristics of gas disaster in the Huaibei coalfield and its control and development technologies. Nat. Hazards. $71(1), 85,2014$.

12. ZHAI C., XIAN W., XU J., WU S. The characteristics and main influencing factors affecting coal and gas outbursts in Chinese Pingdingshan mining region. Nat. Hazards. 82 (1), 507, 2016.

13. DONG G., HU Q., WANG Q., HUANG C. The evolution of ejective folds and their influence on coal and gas outburst. J. China. U. Min. Techno. 41 (6), 912, 2012.

14. AN F., CHENG Y. The Effect of a Tectonic Stress Field on Coal and Gas Outbursts. Scientific. World. J. 2014 (1):1-10, 2014.

15. WEI Y., LIN B., XU J. Gas outburst affected by original rock stress direction. Nat. Hazards. 72, 1063, 2014.

16. ZHAO W., CHENG Y., JIANG H., JIN K., WANG H., WANG L. Role of the rapid gas desorption of coal powders in the development stage of outbursts. J. Nat. Gas. Sci. Eng. 28, 491-501, 2016

17. GODYN K. Structurally altered hard coal in the areas of tectonic disturbances-an initial attempt at classification. Arch. Min. Sci. 61 (3), 677, 2016.

18. GUO H., CHENG Y., REN T., WANG L., YUAN L., JIANG H., LIU H. Pulverization characteristics of coal from a strong outburst-prone coal seam and their impact ongas desorption and diffusion properties. Electrocatalysis. 7 (4), 280, 2016.

19. HUOYIN LI. Major and minor structural features of a bedding shear zone along a coal seam and related gas outburst,
Pingdingshan coalfield,northern China. Int. J. Coal Geol. 47, 101, 2001.

20. WANG G. Discussion on superposed folds in coal mines of China. Earth. Sci. Front. 6 (S1), 175, 1999.

21. ZHANG Z., WU Y. Tectonic-level-control rule and areadividing of coalmine gas occurrence in China. Earth. Sci. Front. 20 (3), 237, 2013.

22. XIE H., XU Y., KANG J. Relationship between vitrinite reflectance of deformed coal and palaeotectonic stress field in western Henan coalfield. Coal. Geo. Explor. 36 (4), 1, 2008.

23. YUAN Z. Yuxi area tectonic characteristics and evolution. Coal. Techno. 29 (3), 167, 2010.

24. RAMSAY J.G. Interference patterns produced by the superposition of folds of similar types. J. Geo. 70, 466, 1962.

25. WANG G., ZHU Y. Study on rheology of coal bed. J. China. U. Min. Techno. 3, 19, 1988.

26. HAO J., YUAN C., ZHANG Z. The tectonic coal and its effects on coal and gas outburst. J. Jiaozuo. Ins. Techno. 19 (6), 403, 2000.

27. SHAO Q., WANG E., WANG H., YIN Q., HU G., LI F. Control to coal and gas outburst of tectonic coal distribution. J. China. Coal. Soc. 35 (2), 250, 2010.

28. CAO Y., HE D., GLICK D.C. Coal and gas outbursts in footwalls of reverse faults. Int. J. Coal Geol. 48, 47, 2001.

29. WANG Z., CHEN L., CHENG C., LI Z. Forecast of Geological Gas Hazards for "Three-Soft" Coal Seams in Gliding Structural Areas. J. China. U. Min. Techno. 17 (4), 484, 2007.

30. KĘDZIOR S., KOTARBA M.J., PĘKAŁA Z. Geology, spatial distribution of methane content and origin of coalbed gases in Upper Carboniferous (Upper Mississippian and Pennsylvanian) strata in the south-eastern part of the Upper Silesian Coal Basin, Poland. Int. J. Coal Geol. 105, 24, 2013.

31. YAO Y., LIU D., YAN T. Geological and hydrogeological controls on the accumulation of coalbed methane in the Weibei field, southeastern Ordos Basin. Int. J. Coal. Geol. 121,148, 2014.

32. GUO D., ZHOU X., SHEN S., ZHANG X. Coal seam methane distribution and its singificance in Pingdingshan mining area. J. Coal. Sci. Eng. (China). 8 (2), 17, 2002.

33. HAO F., LIU M., WEI J., FU Y. The controlling role of gravitational slide structure to coal and gas outburst. J. China. Coal. Soc. 37 (5), 825, 2012. 
